\title{
Inflammation to cancer: The molecular biology in the pancreas (Review)
}

\author{
SUNBIN LING ${ }^{1 *}$, TINGTING FENG ${ }^{2 *}$, KAIQI JIA ${ }^{1}$, YU TIAN $^{1}$ and YAN LI ${ }^{3,4}$ \\ Departments of ${ }^{1}$ General Surgery and ${ }^{2}$ Medical Oncology, The Second Affiliated Hospital of Dalian Medical University, \\ Dalian, Liaoning 116023; ${ }^{3}$ Institute of Cancer Stem Cells; ${ }^{4}$ College of Basic Medical Sciences, \\ Dalian Medical University, Dalian, Liaoning 116044, P.R. China
}

Received July 2, 2013; Accepted March 11, 2014

DOI: $10.3892 / \mathrm{ol} .2014 .2003$

\begin{abstract}
Inflammatory responses are known to be correlated with cancer initiation and progression, and exploration of the route from inflammation to cancer makes a great contribution in elucidating the mechanisms underlying cancer development. Pancreatic cancer (PC) is a lethal disease with a low radical-resection rate and a poor prognosis. As chronic pancreatitis is considered to be a significant etiological factor for PC development, the current review aims to describe the molecular pathways from inflammation to pancreatic carcinogenesis, in support of the strategies for the prevention, diagnosis and treatment of PC.
\end{abstract}

\section{Contents}

1. Introduction

2. Chronic pancreatitis and risk of pancreatic cancer

3. Molecular pathway between chronic pancreatitis and cancer of the pancreas

4. Conclusion

\section{Introduction}

Pancreatic cancer (PC), for which the overall 5-year survival rate among patients is $\sim 6 \%$ (1), has the fourth highest incidence ratio of cancer-related fatalities, with $<10 \%$ of patients having

Correspondence to: Dr Yan Li, Institute of Cancer Stem Cells and College of Basic Medical Sciences, Dalian Medical University, 9 West Section Lvshun South Road, Dalian, Liaoning 116044, P.R. China

E-mail: ly316@126.com

${ }^{*}$ Contributed equally

Key words: inflammation, pancreatic cancer, K-ras, nuclear factor- $\kappa \mathrm{B}$, cyclooxygenase-2, serine protease inhibitor kazal type 1 , reactive oxygen species, proinflammatory cytokines the opportunity of radical surgery at diagnostic presentation. Current evidence has indicated that the associated risk factors include smoking, alcoholism, diabetes mellitus, genetic factors and chronic pancreatitis (CP) (2-6). However, the causes and mechanisms of $\mathrm{PC}$ remain unclear.

Inflammatory responses play a significant role in cancer development, including the initial malignant conversion. The potential association between inflammation and cancer has been observed in various types of malignancies, including persistent Helicobacter pylori infection with gastric carcinoma (7), inflammatory bowel disease with colorectal cancer $(8,9)$ and reflux esophagitis with esophageal adenocarcinoma (10). It is widely believed that tumor initiation is triggered by multiple mutational hits that induce DNA damage and genomic instability. The potential carcinogens produced from inflammatory cells, such as reactive oxygen species (ROS) and reactive nitrogen intermediates, are capable of inducing malignant initiation through accumulation of continuous DNA damage and subsequent abortive repair. Furthermore, the production of growth factors and cytokines during the inflammatory process can enhance the proliferation of initiated cells by eventually converting them to tumor cells (11). Assessing the link between chronic inflammation and tumorigenesis may provide a different approach to understanding the pathological mechanisms of tumor development. Accordingly, the present review discusses the molecular biology of $\mathrm{CP}$ to $\mathrm{PC}$, which may contribute to furthering the clinical diagnosis and therapy.

\section{Chronic pancreatitis and risk of pancreatic cancer}

Several studies have demonstrated a strong link between antecedent $\mathrm{CP}$ and PC. The incidence is variable and the standardized incidence ratio (SIR) has been reported to be between 3.8 (12) and 18.5 (13). In 1993, Lowenfels et al (14) launched an international cohort study with 2,015 patients, demonstrating that the SIR was 14.4. The risk of malignant transformation 10 and 20 years after diagnosis was 1.8 and $4.0 \%$, respectively. However, certain epidemiological factors, including cigarette smoking and alcohol (15), which are considered as cofactors in the development of pancreatitis, are also responsible for the increased PC incidence $(6,16)$.

Additionally, two recent large-sample case-control studies of PC identified that a short temporal history of pancreatitis 
was highly associated with PC (17), indicating that pancreatitis may be an early manifestation of PC in specific individuals. Patients with PC may be diagnosed with $\mathrm{CP}$ in the first diagnosis, while the differential diagnosis between early $\mathrm{CP}$ and $\mathrm{PC}$ is difficult. The misdiagnosis may elevate the correlation of the two.

However, with adjustments or matching variables, including smoking habit and alcohol consumption, the risk of PC increases in patients with CP (18). In patients with hereditary pancreatitis, the lifetime risk of PC is $40 \%$ (19), and similarly, for those patients with tropical pancreatitis, the risk of PC is also high (20). Furthermore, a study by Talamini et al (13) analyzed 715 cases of $\mathrm{CP}$ with a median follow-up of 10 years, observing that the risks of $\mathrm{PC}$ and non-PC were increased as compared with the general population. Notably, the clearly higher incidence of PC indicated that although cigarette smoking contributed to various tumors, there were certain other factors linked to the chronic inflammation of the pancreas, which may be responsible for the increased risk.

In summary, $\mathrm{CP}$ is determinately considered as an independent risk factor for PC. This risk is markedly increased in those patients with hereditary pancreatitis or tropical pancreatitis.

\section{Molecular pathway between chronic pancreatitis and cancer of the pancreas}

With the documented link between CP and PC, the molecular pathway from inflammation to cancer in the pancreas exhibits an increasing significance for deeper analysis. Novel molecular changes have been observed in CP and PC simultaneously, including K-ras mutations $(21,22)$ and serine protease inhibitor Kazal type 1 (SPINK1) gene N34S mutations $(23,24)$. In addition, the cyclooxygenase-2 (COX-2) enzyme and nitric oxide (NO), which are considered to be inflammatory mediators and have been found to be overexpressed in patients with $\mathrm{CP}(25,26)$, may act as key factors in the tumorigenesis in CP. Therefore, further discussion in the present review focuses on the roles of novel molecules in pancreatic tumorigenesis.

\subsection{K-ras}

The Ras family, which consists of three members, known as H-, $\mathrm{N}$ - and K-ras, are proto-oncogenes that encode a highly-homologous group of 21-kDa monomeric, membrane-localized guanosine triphosphate (GTP)-ases. The main function of these proteins is to transmit signals between the extracellular and intracellular environment, acting as a 'molecular switch'. As downstream molecules with normal regulation sustaining the homeostasis associated with cell proliferation and apoptosis, the error state-like point mutation, multiple expression, insertion and transposition of the Ras genes are responsible for the carcinogenesis of numerous organs.

The K-ras gene is located on chromosome 12p12, and is $\sim 45,000$ bp in length. K-ras is the most cancer-related protein in the p21 Ras proteins, existing in two alternatively spliced forms, K-Ras4A and K-Ras4B, which have differing c-terminal residues resulting in differential post-translational modification. Mutations frequently detected in codon 12 ,
13 and 61 of the K-ras gene result in the subsequent translational product remaining in the GTP-bound (27), activated state, which may activate the downstream pathways, including Raf/MEK/extracellular signal-regulated kinase (ERK) (28-30) and Ras/phosphatidylinositol-3-kinase (PI3K)/Akt $(31,32)$. The complex intracellular regulations originating from the K-ras mutation finally result in a proliferation and apoptosis-related malignant transformation in certain cells $(32,33)$. Constitutive activation of K-ras has been observed in specific pathological changes in the pancreas, including $\mathrm{CP}$, pancreatic intraepithelial neoplasia (PanIN) and PC (34), among which the simultaneous overexpression of K-ras exhibiting the potential linkage, has attracted widespread attention. Mu et al (35) investigated the clinical significance of K-ras gene mutation detection in patients with $\mathrm{CP}$ and observed that screening for the K-ras mutation may be useful in identifying patients with pancreatitis that are at a high risk for developing cancer. In 2007, Guerra et al (36) established a mouse model with CP induced by caerulein treatment, and observed that the chronic inflammation in the pancreas could facilitate the differentiation of acinar/centroacinar or their precursor cells into ductal-like cells, resulting in PanINs and pancreatic ductal adenocarcinoma (PDA) by the selective expression of an endogenous K-RasG12V oncogene in adult mice. The formation of PanINs followed a defined progression from lowto high-grade lesions that resulted in the appearance of invasive PDA by completely depending on K-RasG12Vgeo expression, as reported similarly in other studies (21,37). Guerra et al (36) also assessed the cooperation between K-RasG12V expression and p53 inactivation, observing that the additional mutation of p53 could strongly enhance the metastatic properties of $\mathrm{K}-\mathrm{R}$ asG12V-induced PDA. As reviewed in these studies, it is now accepted that the K-Ras oncogene forms the linkage between CP and PDA. Recently, Guerra et al (38) completed a further study to approach the molecular pathways from $\mathrm{CP}$ to $\mathrm{PC}$ with expression of a resident K-ras oncogene in adult mice. The study demonstrated that the K-ras mutation could initiate murine PanINs (mPanINs) and murine PDAC (mPDAC) in adult mice with pre-existing pancreatic damage and an inflammatory response. Furthermore, the study also observed that the loss of p16Ink4a/p19Arf and Trp53 in adult acinar cells only contributed to the mPanIN and mPDAC development in the presence of K-Ras oncogenes, which may confirm the key role of K-ras in the carcinogenesis in the pancreas. Finally, oncogene-induced senescence, a natural defense mechanism against tumor development (39), was observed to be repressed by the inflammatory response of pancreatitis, and may be one of the mechanisms by which pancreatitis-induced inflammation contributes to $\mathrm{PC}$, cooperating with simultaneous expression of the K-ras oncogene.

Recent studies described a new signaling pathway, the epidermal growth factor receptor (EGFR) signaling pathway, which was indicated to be required for K-ras-driven tumorigenesis and inflammation-associated tumorigenesis in the pancreas $(40,41)$. In the mutant K-ras-driven PDA model, EGFR controls the differentiation of neoplastic precursors and induces tumor initiation, following which, EGFR promotes cancer progression by activating ERK. In addition, certain other signaling pathways are indicated in the participation of K-ras-induced pancreatic tumorigenesis, including the nuclear factor- $\kappa \mathrm{B}(\mathrm{NF}-\kappa \mathrm{B})$ and Notch signaling pathways $(42,43)$. 
The K-ras oncogene is widely believed to be one of the initial components in pancreatic carcinogenesis, as of which several trials have been reported regarding the clinical applications $(44,45)$. However, how the activated K-ras oncogenes are induced by the inflammatory microenvironment remains unclear. More notably, to elucidate the precise timing at which the K-ras mutations become detectable during the chronic inflammatory process will contribute to the early diagnosis of PC. Consequently, much more extensive work on the role of $\mathrm{K}$-ras in pancreatic diseases will be involved in future studies.

\subsection{COX-2}

COX, also known as prostaglandin-endoperoxide synthetase, is the rate-limiting enzyme responsible for converting arachidonic acid to prostaglandins, leukotrienes and thromboxanes, which are considered to be the proinflammatory cytokines (46). Two isoforms of COX exist. COX-1 is constitutively expressed in numerous tissues and always plays the 'house-keeping' role in tissue homeostasis, whereas COX-2 is an inducible isoform observed to be overexpressed in numerous pathological changes, including inflammation and tumorigenesis (47).

COX-2 expression is elevated in response to a variety of proinflammatory stimuli, including interleukin-1 (IL-1), IL-6, tumor necrosis factor- $\alpha(\mathrm{TNF}-\alpha)$ and transforming growth factor- $\beta$ (TGF- $\beta$ ) $(48,49)$. Several studies have observed the overexpression of COX-2 in CP $(25,50)$, and the COX-2 inhibitors attenuating the severity of acute pancreatitis in a rat model have indicated the correlation between $\mathrm{COX}-2$ and the genesis of pancreatitis (51). Additionally, COX-2 has been found to be upregulated in PanIN (52), intraductal papillary mucinous neoplasm (IPMN) (53) and human PC tissue $(53,54)$. Early suppression of COX-2 may contribute to preventing the progression of inflammatory and pre-malignant lesions to malignance in the pancreas (47-49). COX-2 promotes cell proliferation (58), inhibits apoptosis (59) and facilitates angiogenesis by increasing vascular endothelial growth factor (VEGF) production (60). Previously, a mouse model (61) was generated, in which the overexpression of COX-2 was under the control of a bovine keratin 5 promoter driving pancreatic acinar-to-ductal metaplasia, which revealed that the elevation of COX-2 was significantly correlated with the metaplasia-dysplasia progressing in the exocrine pancreas. However, the precise mechanism by which COX-2 promotes $\mathrm{PC}$ growth is unclear.

Thus, COX-2 conducts the definite linkage between inflammation and cancer in the pancreas. However, a number of laboratory and clinical studies, whose conclusions are controversial, have approached the therapeutic significance of targeting COX-2 activity for PC (62-67), and it requires more experimental evidence to confirm whether targeting COX-2 can be applied in clinical treatment.

\subsection{NF-кB}

$\mathrm{NF}-\kappa \mathrm{B}$ is a family of transcription factors, including $\mathrm{NF}-\kappa \mathrm{B} 1$, $\mathrm{NF}-\kappa \mathrm{B} 2$, Rel A, c-Rel and Rel B. These proteins are constitutively expressed in the cytoplasm of eukaryotic cells in an unactivated state as a result of combining with an inhibitory protein, inhibitor $\kappa \mathrm{B}(\mathrm{I} \kappa \mathrm{B})$. The exact mechanism of NF- $\kappa \mathrm{B}$ activation is complex and not completely clear. The impact of various pathogenic stimuli, including the proinflammatory factors TNF- $\alpha$, IL-1 and bacterial lipopolysaccharide, enabling phosphorylation of I $\mathrm{B} \alpha$ subsequently results in the degradation of $\mathrm{I} \kappa \mathrm{B} \alpha$ and exposures the sequence for DNA binding and nuclear translocation in $\mathrm{NF}_{-} \kappa \mathrm{B}$. Activated and nuclear translocated $\mathrm{NF}-\kappa \mathrm{B}$, as a transcription factor, plays a significant role in the transcriptional control of certain inflammatory and cancer-related genes, including COX-2 (68), IL-8 (69), inducible NO synthase, cyclin D1 (68), c-Myc and VEGF. These molecules, by which NF- $\kappa \mathrm{B}$ promotes $\mathrm{PC}$ growth, are upregulated and responsible for cell cycle control, angiogenesis and the inhibition of apoptosis in $\mathrm{PC}$ progression. Genetic mutations in $\mathrm{NF}-\kappa \mathrm{B}, \mathrm{I} \kappa \mathrm{B}$ kinase (IKK) or upstream components of its signaling system have rarely been observed. Otherwise, exposure to the proinflammatory microenvironment resulting in activation of $\mathrm{NF}-\kappa \mathrm{B}$ in cancer has been widely hypothesized and demonstrated $(70,71)$. The molecules for the activation of the IKK/NF- $\mathrm{B}$ signaling pathway include growth factors, cytokines, lymphokines and microRNA (72), most of which may bridge the gap between inflammation and cancer.

Constitutive activation of $\mathrm{NF}-\kappa \mathrm{B}$ has been observed in several PC cell lines (73) and human PC tissue (74-76). The proinflammatory cytokine-paracrine loops established by inflammatory, immune and cancer cells potently activate $\mathrm{NF}-\kappa \mathrm{B}$ in PC $(11,77)$. The autocrine secretion of IL-1 $\alpha$, induced by activator protein-1 activity, has been demonstrated to play a key role in the activation of $N F-\kappa B$ in metastatic PC cell lines (78). In turn, the activation of $\mathrm{NF}-\kappa \mathrm{B}$ can enhance expression of IL- $1 \alpha$, which results in a positive feedback loop for the constitutive $\mathrm{NF}-\kappa \mathrm{B}$ activation in PC. Additionally, IL-1 $\alpha$ can enhance the expression of several NF- $\mathrm{B}$-regulated genes, including IL-8 and VEGF, which are responsible for the metastatic processes and angiogenesis of cancer, in PC cells (79). In conclusion, the IL- $1 \alpha-\mathrm{NF}-\kappa \mathrm{B}$ positive feedback loop makes great contributions to support the malignant phenotype in PC.

By contrast, previous studies have shown the essential role of the NF- $\kappa \mathrm{B}$ pathway in K-ras-mutant PCs $(43,80)$. As there have been less therapeutic strategies of PC-targeting on the K-ras signaling pathway, the inhibition of $N F-\kappa B$ is an attractive strategy for the treatment of K-ras-dependent PC.

\subsection{SPINK1}

SPINK1 has been identified as a trypsin inhibitor and is also known as a pancreatic secretory trypsin inhibitor (81). SPINK1 is secreted by the acinar cells of the exocrine pancreas into the pancreatic juice and is able to bind to trypsin to inhibit its activity. SPINK1 protects the pancreas from the impact of prematurely activated trypsinogen, and SPINK1 mutations, particularly the N34S mutation (82), have also been reported to lower the threshold for pancreatitis from other genetic or environmental factors (83) instead of initiating the development of CP.

SPINK1 mutations in patients with pancreatitis are firmly demonstrated in numerous studies (82,84-86). Notably, the intronic mutations, including N34S, IVS1-37T $>$ C and 
IVS3-69insTTTT, do not affect the mRNA expression of the SPINK1 gene, and these mutations have not been observed to be capable of affecting the binding affinity and inhibitory activity of SPINK1 to trypsin. Ohmuraya et al (87) created a mouse model with deficient SPINK3 (a mouse homologue gene of human SPINK1) and showed that excessive autophagy in pancreatic acinar cells could be induced by the loss of the regulation of SPINK3, indicating that SPINK3 may act as a suppressor of autophagy. Therefore, the pathogenesis of pancreatitis may be more complex, and further studies will be required to elucidate the role of SPINK1 in the onset of pancreatitis.

Previously, Rebours et al (88) described the case of a CP-diagnosed patient with an N34S mutation of SPINK1. Cystic fibrosis transmembrane conductance regulator minor mutations were found in the multifocal moderate-dysplastic lesions of PanIN-2 in the duct epithelium following a left pancreatectomy. Shimosegawa et al (89) examined whether the SPINK1 gene N34S mutation could be a risk factor for $\mathrm{PC}$ in patients with $\mathrm{CP}$. The study investigated the development of PC in three out of $16 \mathrm{CP}$ patients with the $\mathrm{N} 34 \mathrm{~S}$ mutation (18.8\%), while only three of $216 \mathrm{CP}$ patients without the SPINK1 mutation (1.4\%) developed PC, indicating that the N34S mutation of the SPINK1 gene may be a significant risk factor for the development of $\mathrm{PC}$ in patients with $\mathrm{CP}$. By contrast, SPINK1 itself has been shown to have growth factor activity in various cell lines, including certain cancer cells $(90,91)$. SPINK1 is described as a ligand for the EGFR. Ozaki et al (91) observed the increase in the cell numbers of PC cell lines following treatment with SPINK1. The results of their subsequent study demonstrate that SPINK1 stimulates the proliferation of PC cells through EGFR and its downstream signal molecules. The immunohistochemical study showed that SPINK1 and EGFR are co-expressed not only in pancreatic tubular adenocarcinoma, but also in PanINs (92). As EGFR is confirmed to be overexpressed in the tissues of CP and PC $(93,94)$, and SPINK1 is produced by the acinar cells and is then secreted into the pancreatic duct, the interaction between SPINK1 and EGFR may be involved in the malignant transformation of normal pancreatic cells during the inflammatory process. A high level of SPINK1 expression has been reported to be associated with cancer progression, tumor recurrence and patient survival rates in certain other cancers, indicating that SPINK1 has additional functions in extrapancreatic cancers $(95,96)$.

In summary, SPINK1 is described as an inhibitor of the onset of pancreatitis, and the mutation of SPINK1 is able to lower the threshold for pancreatitis from other genetic or environmental factors. In addition, SPINK1 itself can promote PC development through the EGFR pathway, while the other roles of SPINK1 in inflammatory incidence and tumorigenesis remain unknown. More laboratorial and clinical studies are required to support the role of SPINK1 between pancreatitis and PC.

\section{5. $\operatorname{ROS}$}

ROS are highly reactive oxygen metabolites such as the superoxide radical $\left(\mathrm{O}_{2}^{-}\right)$the hydroxyl radical $\left(\mathrm{OH}^{-}\right)$hydrogen peroxide $\left(\mathrm{H}_{2} \mathrm{O}_{2}\right)$ and trioxygen $\left(\mathrm{O}_{3}\right)$. ROS are produced in mitochondria as by-products of oxidative phosphorylation, and are part of the normal cellular metabolism. In inflammatory processes ROS are produced by phagocytes. Additionally, inflammatory cells may use cytokines, including TNF- $\alpha$ and TGF- $\beta$ (97), to stimulate ROS accumulation in surrounding epithelial cells. In cancer cells, comparatively high levels of ROS can also result from increased metabolic activity, mitochondrial dysfunction, oncogene activity and the increased activity of oxidases, COXs and lipoxygenases $(99,99)$.

ROS can oxidize lipids in the cell membrane, oxidatively modify protein, depolarize the mitochondrial membrane and induce DNA fragmentation to directly damage DNA and induce genomic instability (100). In addition to ROS-induced direct DNA damage, certain by-products produced from ROS-generated lipid peroxidation, including malondialdehyde (MDA) and 8-oxodeoxyguanosine, also known as oxidized DNA adducts, can be potent carcinogenic molecules (101). Varying levels of ROS always result in different effects on cell proliferation. ROS at acute high levels may act as potent cytotoxic molecules inducing cell apoptosis (102). Chronic low levels of ROS can affect genome stability and cause tumorigenesis $(103,104)$, emphasizing the role of ROS in the initiation of malignancy in CP tissues.

Higher levels of oxidative DNA adducts and MDA have been found in patients with CP (105) and also in human pancreatic tumor tissue (106). Identically, the primary intracellular antioxidant enzymes, superoxide dismutase (SOD), catalase and glutathione peroxidase, are detected in the pancreas, and a gradually decreased expression of the three antioxidant enzymes has been shown in pancreatic cells from the normal pancreas to CP to PC (107). The upregulation of SODs can effectively suppress $\mathrm{PC}$ growth in vitro and in vivo (108). It has been indicated that chronic low levels of ROS promote malignant initiation and cancer cell proliferation in the pancreas. By contrast, ROS can active several signaling pathways, including the mitogen-activated protein kinase, $\mathrm{PI} 3 \mathrm{~K} / \mathrm{Akt} \mathrm{NF}-\kappa \mathrm{B}$ signaling, protein kinase $\mathrm{C}$ and p53 signaling pathways (109-111), which may tend to activate cell survival or cell death. ROS can participate in the apoptotic or anti-apoptotic mechanisms in oxidative stress-targeting therapeutics or oncogene-induced malignant transformation (112-115). Therefore, the actual role of ROS in pancreatitis-derived PC was really determined by the extent of accumulation and the regulation of activity. The balanced regulation of ROS in pancreatitis and PC should be further investigated, which may also be regarded as the potential therapy target for PC.

\subsection{Proinflammatory cytokines}

Proinflammatory cytokines that are secreted by immune and inflammatory cells are significant components in the inflammation and tumor microenvironment. Several cytokines, including IL-1, TNF, IL-6 and IL-23, are critical for inflammation and tumor growth. Varying cytokines affect certain downstream effectors, including $\mathrm{NF}-\kappa \mathrm{B}$, activator protein-1, signal transducers and activators of transcription and SMAD transcription factors, to exhibit either promotion or inhibition effects in tumor progression $(11,116)$. By contrast, oncoproteins, such as Ras and Myc, can also promote the secretion 
of proinflammatory cytokines, which have direct effects on cancer cell growth and survival (117). Altogether, proinflammatory cytokines significantly mediate the mechanisms of inflammation-related tumor initiation and promotion.

Significantly higher levels of TNF- $\alpha$, IL-1, IL-6 and IL-8 have been observed in patients with $\mathrm{CP}$ and $\mathrm{PC}$ compared with healthy controls (118-121). IL-1 acting through the IL-1 receptor type I can promote the invasion and angiogenesis of PC cells (123). The cyst fluid IL-1 levels predict the risk of carcinoma in IPMN, indicating that IL-1 may facilitate malignant transformation in the pancreas (123). TNF- $\alpha$ is classically considered to be an inhibitor of the apoptosis of cancer cells by activating the expression of NF- $\mathrm{B}$ (124-126). Additionally, the inflammatory-derived $\mathrm{TNF} \alpha$ is able to stimulate migration and induce the epithelial-mesenchymal transition of human pancreatic carcinoma cells (127). IL-6 has been identified as a growth factor that enhances PC cell proliferation $(118,128,129)$. An elevated IL-6 level is correlated with advanced $\mathrm{PC}$, which is represented by cachexia and a poor-life status (130). IL-8, also known as chemokine (C-X-C motif) ligand 8 (CXCL-8), is a CXC chemokine that is produced by numerous types of cells in response to inflammatory stimuli. IL-8 plays a significant role in neutrophil chemotaxis and activation. In addition to its inflammatory role, IL- 8 has been found to be an autocrine growth factor in PC $(131,132)$. The expression of IL-8 is driven by NF- $\kappa \mathrm{B}$ activation (133), and numerous cytokines, including TNF- $\alpha$ and leukemia inhibitory factor, can enhance the expression of IL-8 (131). IL-8 acts as a significant effector molecule bridging the gap between inflammation and cancer in the pancreas.

Recently, more cytokines have been identified that are correlated with the clinical stage and prognosis in patients with PC (134-136). Cytokines, as molecules derived from inflammatory cells and immune cells, should be highlighted as prospects for the future exploration of the molecular mechanism from inflammation to cancer in the pancreas.

\section{Conclusion}

Despite advances in oncology and surgery, patients with PC frequently have a poor performance and clinical prognosis. Clinical evidence has confirmed the correlation between inflammation and pancreatic tumorigenesis. Inflammatory responses play a significant role in PC initiation and progression. In turn, cancer-induced inflammatory microenvironment or secreted inflammatory molecules can enhance the proliferation of cancer cells and promote the inflammatory responses. Exploring the variation in molecular expression and function from inflammation to cancer may aid in the development of a route to reveal the causes and mechanisms of PC. Inflammation-targeted treatments and examinations exhibit an appealing perspective in the therapy and diagnosis (121) of inflammation-related cancer in the pancreas $(135,137-139)$. In addition, great importance should be attached to the inflammatory responses in the process of assigning chemotherapies and surgeries for PC treatment. The treatment of inflammatory changes may be necessary for the preventive and therapeutic schedules of PC.

\section{Acknowledgements}

This study was supported by grants from the National Natural Science Foundation of China (81272368 and 81102069).

\section{References}

1. Siegel R, Ma J, Zou Z and Jemal A: Cancer statistics, 2014. CA Cancer J Clin 64: 9-29, 2014.

2. Batty GD, Kivimaki M, Morrison D, et al: Risk factors for pancreatic cancer mortality: extended follow-up of the original Whitehall Study. Cancer Epidemiol Biomarkers Prev 18: 673-675, 2009.

3. Landi S: Genetic predisposition and environmental risk factors to pancreatic cancer: A review of the literature. Mutat Res 681: 299-307, 2009.

4. Lowenfels AB and Maisonneuve P: Epidemiology and risk factors for pancreatic cancer. Best Pract Res Clin Gastroenterol 20: 197-209, 2006.

5. Genkinger JM, Spiegelman D, Anderson KE, et al: Alcohol intake and pancreatic cancer risk: a pooled analysis of fourteen cohort studies. Cancer Epidemiol Biomarkers Prev 18: 765-776, 2009.

6. Hassan MM, Bondy ML, Wolff RA, et al: Risk factors for pancreatic cancer: case-control study. Am J Gastroenterol 102: 2696-2707, 2007.

7. Peek RM, Jr. and Crabtree JE: Helicobacter infection and gastric neoplasia. J Pathol 208: 233-248, 2006.

8. Eaden JA, Abrams KR and Mayberry JF: The risk of colorectal cancer in ulcerative colitis: a meta-analysis. Gut 48: 526-535, 2001.

9. Canavan C, Abrams KR and Mayberry J: Meta-analysis: colorectal and small bowel cancer risk in patients with Crohn's disease. Aliment Pharmacol Ther 23: 1097-1104, 2006.

10. Solaymani-Dodaran M, Logan RF, West J, Card T and Coupland C: Risk of oesophageal cancer in Barrett's oesophagus and gastro-oesophageal reflux. Gut 53: 1070-1074, 2004.

11. Grivennikov SI, Greten FR and Karin M: Immunity, inflammation, and cancer. Cell 140: 883-899, 2010.

12. Ekbom A, McLaughlin JK, Karlsson BM, et al: Pancreatitis and pancreatic cancer: a population-based study. J Natl Cancer Inst 86: 625-627, 1994.

13. Talamini G, Falconi M, Bassi C, et al: Incidence of cancer in the course of chronic pancreatitis. Am J Gastroenterol 94: 1253-1260, 1999.

14. Lowenfels AB, Maisonneuve P, Cavallini G, et al: Pancreatitis and the risk of pancreatic cancer. International Pancreatitis Study Group. N Engl J Med 328: 1433-1437, 1993.

15. Maisonneuve P, Lowenfels AB, Müllhaupt B, et al: Cigarette smoking accelerates progression of alcoholic chronic pancreatitis. Gut 54: 510-514, 2005.

16. Doll R, Peto R, Hall E, Wheatley K and Gray R: Mortality in relation to consumption of alcohol: 13 years' observations on male British doctors. BMJ 309: 911-918, 1994.

17. Bracci PM, Wang F, Hassan MM, Gupta S, Li D and Holly EA: Pancreatitis and pancreatic cancer in two large pooled case-control studies. Cancer Causes Control 20: 1723-1731, 2009.

18. Bansal P and Sonnenberg A: Pancreatitis is a risk factor for pancreatic cancer. Gastroenterology 109: 247-251, 1995.

19. Lowenfels AB, Maisonneuve P, DiMagno EP, Elitsur Y, Gates LK Jr, Perrault J and Whitcomb DC: Hereditary pancreatitis and the risk of pancreatic cancer. International Hereditary Pancreatitis Study Group. J Natl Cancer Inst 89: 442-446, 1997.

20. Chari ST, Mohan V, Pitchumoni CS, Viswanathan M, Madanagopalan N and Lowenfels AB: Risk of pancreatic carcinoma in tropical calcifying pancreatitis: an epidemiologic study. Pancreas 9: 62-66, 1994.

21. Ji B, Tsou L, Wang H, Gaiser S, et al: Ras activity levels control the development of pancreatic diseases. Gastroenterology 137: 1072-1082, 2009.

22. Wang Z, Ali S, Banerjee S, et al: Activated K-Ras and INK4a/ Arf deficiency promote aggressiveness of pancreatic cancer by induction of EMT consistent with cancer stem cell phenotype. J Cell Physiol 228: 556-562, 2013.

23. Bishop M, Xenoulis P and Steiner JM: Association between this SPINK1 variant and clinically detectable pancreatitis. J Vet Intern Med 27: 427-428, 2013. 
24. Hucl T, Jesnowski R, Pfützer RH, Elsässer HP and Löhr M: SPINK1 variants in young-onset pancreatic cancer. J Gastroenterol 42: 599, 2007.

25. Schlosser W, Schlosser S, Ramadani M, Gansauge F, Gansauge S and Beger HG: Cyclooxygenase-2 is overexpressed in chronic pancreatitis. Pancreas 25: 26-30, 2002.

26. Vinokurova LV, Berezina OI, Drozdov VN, Petrakov AV and Nilova TV: Nitric oxide and indicators of oxidative stress in patients with exacerbation of chronic pancreatitis. Eksp Klin Gastroenterol 2: 75-81, 2011 (In Russian).

27. Bernards A and Settleman J: GAP control: regulating the regulators of small GTPases. Trends Cell Biol 14: 377-385, 2004.

28. Voice JK, Klemke RL, Le A and Jackson JH: Four human ras homologs differ in their abilities to activate Raf-1, induce transformation, and stimulate cell motility. J Biol Chem 274: 17164-17170, 1999.

29. Maekawa M, Nishida E and Tanoue T: Identification of the anti-proliferative protein Tob as a MAPK substrate. J Biol Chem 277: 37783-37787, 2002.

30. Roux PP, Ballif BA, Anjum R, Gygi SP and Blenis J: Tumor-promoting phorbol esters and activated Ras inactivate the tuberous sclerosis tumor suppressor complex via p90 ribosomal S6 kinase. Proc Natl Acad Sci USA 101: 13489-13494, 2004.

31. Rodriguez-Viciana P, Warne PH, Vanhaesebroeck B Waterfield MD and Downward J: Activation of phosphoinositide 3-kinase by interaction with Ras and by point mutation. EMBO J 15: 2442-2451, 1996.

32. Brognard J, Clark AS, Ni Y and Dennis PA: Akt/protein kinase B is constitutively active in non-small cell lung cancer cells and promotes cellular survival and resistance to chemotherapy and radiation. Cancer Res 61: 3986-3997, 2001.

33. Rodriguez-Viciana P, Warne PH, Khwaja A, et al: Role of phosphoinositide 3-OH kinase in cell transformation and control of the actin cytoskeleton by Ras. Cell 89: 457-467, 1997.

34. Mulligan NJ, Yang S, Andry C, Klein M, and O'Brien MJ: The role of p21ras in pancreatic neoplasia and chronic pancreatitis. Hum Pathol 30: 602-610, 1999.

35. Mu DQ, Peng YS, and Xu QJ: Values of mutations of K-ras oncogene at codon 12 in detection of pancreatic cancer: 15-year experience. World J Gastroenterol 10: 471-475, 2004.

36. Guerra C, Schuhmacher AJ, Cañamero M, et al: Chronic pancreatitis is essential for induction of pancreatic ductal adenocarcinoma by K-Ras oncogenes in adult mice. Cancer Cell 11: 291-302, 2007.

37. Logsdon CD and Ji B: Ras activity in acinar cells links chronic pancreatitis and pancreatic cancer. Clin Gastroenterol Hepatol 7 (11 Suppl): S40-S43, 2009

38. Guerra C, Collado M, Navas C, et al: Pancreatitis-induced inflammation contributes to pancreatic cancer by inhibiting oncogene-induced senescence. Cancer Cell 19: 728-739, 2011

39. Collado M and Serrano M: Senescence in tumours: evidence from mice and humans. Nat Rev Cancer 10: 51-57, 2010.

40. Navas C, Hernández-Porras I, Schuhmacher AJ, Sibilia M, Guerra C and Barbacid M: EGF receptor signaling is essential for k-ras oncogene-driven pancreatic ductal adenocarcinoma. Cancer Cell 22: 318-330, 2012

41. Ardito CM, Grüner BM, Takeuchi KK, et al: EGF receptor is required for KRAS-induced pancreatic tumorigenesis. Cancer Cell 22: 304-317, 2012.

42. Wang Z, Banerjee S, Ahmad A, et al: Activated K-ras and INK4a/ Arf deficiency cooperate during the development of pancreatic cancer by activation of Notch and NF- $\mathrm{KB}$ signaling pathways. PLoS One 6: e20537, 2011.

43. Daniluk J, Liu Y, Deng D, et al: An NF-кB pathway-mediated positive feedback loop amplifies Ras activity to pathological levels in mice. J Clin Invest 122: 1519-1528, 2012.

44. Friday BB and Adjei AA: K-ras as a target for cancer therapy. Biochim Biophys Acta 1756: 127-144, 2005.

45. Kamisawa T, Takuma K, Tabata T, Egawa N and Yamaguchi T: Long-term follow-up of chronic pancreatitis patients with K-ras mutation in the pancreatic juice. Hepatogastroenterology 58 174-176, 2011.

46. Prescott SM and Fitzpatrick FA: Cyclooxygenase-2 and carcinogenesis. Biochim Biophys Acta 1470: M69-M78, 2000.

47. Williams CS, Mann M and DuBois RN: The role of cyclooxygenases in inflammation, cancer, and development. Oncogene 18: 7908-7916, 1999.

48. Diaz A, Chepenik KP, Korn JH, Reginato AM and Jimenez SA Differential regulation of cyclooxygenases 1 and 2 by interleukin- 1 beta, tumor necrosis factor-alpha, and transforming growth factor-beta 1 in human lung fibroblasts. Exp Cell Res 241: 222-229, 1998.
49. Aoki H, Ohnishi H, Hama K, et al: Cyclooxygenase-2 is required for activated pancreatic stellate cells to respond to proinflammatory cytokines. Am J Physiol Cell Physiol 292: C259-C268, 2007.

50. Koliopanos A, Friess H, Kleeff J, Roggo A, Zimmermann A and Büchler MW: Cyclooxygenase 2 expression in chronic pancreatitis: correlation with stage of the disease and diabetes mellitus. Digestion 64: 240-247, 2001

51. O'Brien G, Shields CJ, Winter DC, Dillon JP, Kirwan WO and Redmond HP: Cyclooxygenase-2 plays a central role in the genesis of pancreatitis and associated lung injury. Hepatobiliary Pancreat Dis Int 4: 126-129, 2005

52. Albazaz R, Verbeke CS, Rahman SH and McMahon MJ: Cyclooxygenase-2 expression associated with severity of PanIN lesions: a possible link between chronic pancreatitis and pancreatic cancer. Pancreatology 5: 361-369, 2005.

53. Niijima M, Yamaguchi T, Ishihara T, Hara T, Kato K, Kondo F and Saisho H: Immunohistochemical analysis and in situ hybridization of cyclooxygenase-2 expression in intraductal papillary-mucinous tumors of the pancreas. Cancer 94: 1565-1573, 2002

54. Molina MA, Sitja-Arnau M, Lemoine MG, Frazier ML and Sinicrope FA: Increased cyclooxygenase-2 expression in human pancreatic carcinomas and cell lines: growth inhibition by nonsteroidal anti-inflammatory drugs. Cancer Res 59: 4356-4362, 1999.

55. Kokawa A, Kondo H, Gotoda $\mathrm{T}$, et al: Increased expression of cyclooxygenase- 2 in human pancreatic neoplasms and potential for chemoprevention by cyclooxygenase inhibitors. Cancer 91: 333-338, 2001.

56. Hillion J, Smail SS, Di Cello F, et al: The HMGA1-COX-2 axis: a key molecular pathway and potential target in pancreatic adenocarcinoma. Pancreatology 12: 372-379, 2012.

57. Kirane A, Toombs JE, Ostapoff $\mathrm{K}$, et al: Apricoxib, a novel inhibitor of COX-2, markedly improves standard therapy response in molecularly defined models of pancreatic cancer. Clin Cancer Res 18: 5031-5042, 2012

58. Kong G, Kim EK, Kim WS, et al: Role of cyclooxygenase-2 and inducible nitric oxide synthase in pancreatic cancer. J Gastroenterol Hepatol 17: 914-921, 2002.

59. Ding XZ, Tong WG and Adrian TE: Blockade of cyclooxygenase- 2 inhibits proliferation and induces apoptosis in human pancreatic cancer cells. Anticancer Res 20: 2625-2631, 2000.

60. Eibl G, Bruemmer D, Okada Y, et al: PGE(2) is generated by specific COX-2 activity and increases VEGF production in COX-2-expressing human pancreatic cancer cells. Biochem Biophys Res Commun 306: 887-897, 2003.

61. Colby JK, Klein RD, McArthur MJ, et al: Progressive metaplastic and dysplastic changes in mouse pancreas induced by cyclooxygenase-2 overexpression. Neoplasia 10: 782-796, 2008.

62. Furukawa F, Nishikawa A, Lee IS, et al: A cyclooxygenase-2 inhibitor, nimesulide, inhibits postinitiation phase of $\mathrm{N}$-nitrosobis(2-oxopropyl)amine-induced pancreatic carcinogenesis in hamsters. Int J Cancer 104: 269-273, 2003.

63. Anderson KE, Johnson TW, Lazovich D and Folsom AR Association between nonsteroidal anti-inflammatory drug use and the incidence of pancreatic cancer. J Natl Cancer Inst 94: 1168-1171, 2002

64. Wenger FA, Kilian M, Achucarro P, et al: Effects of Celebrex and Zyflo on BOP-induced pancreatic cancer in Syrian hamsters. Pancreatology 2: 54-60, 2002

65. Wei D, Wang L, He Y, Xiong HQ, Abbruzzese JL and Xie K: Celecoxib inhibits vascular endothelial growth factor expression in and reduces angiogenesis and metastasis of human pancreatic cancer via suppression of Sp1 transcription factor activity. Cancer Res 64: 2030-2038, 2004.

66. Jacobs EJ, Connell CJ, Rodriguez C, et al: Aspirin use and pancreatic cancer mortality in a large United States cohort. J Natl Cancer Inst 96: 524-528, 2004.

67. Schernhammer ES, Kang JH, Chan AT, et al: A prospective study of aspirin use and the risk of pancreatic cancer in women. J Natl Cancer Inst 96: 22-28, 2004.

68. Yamamoto Y and Gaynor RB: Therapeutic potential of inhibition of the NF-kappaB pathway in the treatment of inflammation and cancer. J Clin Invest 107: 135-142, 2001.

69. Shi Q, Le X, Abbruzzese JL, et al: Cooperation between transcription factor AP-1 and NF-kappaB in the induction of interleukin- 8 in human pancreatic adenocarcinoma cells by hypoxia. J Interferon Cytokine Res 19: 1363-1371, 1999.

70. Karin M, Cao Y, Greten FR and Li ZW: NF-kappaB in cancer: from innocent bystander to major culprit. Nat Rev Cancer 2: 301-310, 2002

71. Karin M: Nuclear factor-kappaB in cancer development and progression. Nature 441: 431-436, 2006. 
72.Lu Z, Li Y, Takwi A, et al: miR-301a as an NF- $\mathrm{kB}$ activator in pancreatic cancer cells. EMBO J 30: 57-67, 2011.

73.Liptay S, Weber CK, Ludwig L, et al: Mitogenic and antiapoptotic role of constitutive NF-kappaB/Rel activity in pancreatic cancer. Int J Cancer 105: 735-746, 2003

74. Fujioka S, Sclabas GM, Schmidt C, et al: Function of nuclear factor kappaB in pancreatic cancer metastasis. Clin Cancer Res 9: 346-354, 2003.

75.Hoffmann A and Baltimore D: Circuitry of nuclear factor kappaB signaling. Immunol Rev 210: 171-186, 2006.

76. Qing G and Xiao G: Essential role of IkappaB kinase alpha in the constitutive processing of NF-kappaB2 p100. J Biol Chem 280: 9765-9768, 2005.

77. Carbone C and Melisi D: NF- $\mathrm{kB}$ as a target for pancreatic cancer therapy. Expert Opin Ther Targets 16 (Suppl 2): S1-S10, 2012.

78. Niu J, Li Z, Peng B and Chiao PJ: Identification of an autoregulatory feedback pathway involving interleukin-1alpha in induction of constitutive NF-kappaB activation in pancreatic cancer cells. J Biol Chem 279: 16452-16462, 2004.

79. Melisi D, Niu J, Chang Z, et al: Secreted interleukin-1alpha induces a metastatic phenotype in pancreatic cancer by sustaining a constitutive activation of nuclear factor-kappaB. Mol Cancer Res 7: 624-633, 2009.

80. Barbie DA, Tamayo P, Boehm JS, et al: Systematic RNA interference reveals that oncogenic KRAS-driven cancers require TBK1. Nature 462: 108-112, 2009.

81. Kazal LA, Spicer DS and Brahinsky RA: Isolation of a crystalline trypsin inhibitor-anticoagulant protein from pancreas. J Am Chem Soc 70: 3034-3040, 1948.

82. Witt H, Luck W, Hennies HC, et al: Mutations in the gene encoding the serine protease inhibitor, Kazal type 1 are associated with chronic pancreatitis. Nat Genet 25: 213-216, 2000.

83. Schneider A, Barmada MM, Slivka A, Martin JA and Whitcomb DC: Clinical characterization of patients with idiopathic chronic pancreatitis and SPINK1 mutations. Scand J Gastroenterol 39: 903-904, 2004.

84. Chen JM, Mercier B, Audrezet MP, et al: Mutations of the pancreatic secretory trypsin inhibitor (PSTI) gene in idiopathic chronic pancreatitis. Gastroenterology 120: 1061-1064, 2001.

85.Pfützer RH, Barmada MM, Brunskill AP, et al: SPINK1/PSTI polymorphisms act as disease modifiers in familial and idiopathic chronic pancreatitis. Gastroenterology 119: 615-623, 2000.

86. Kuwata K, Hirota M, Nishimori I, Otsuki M and Ogawa M Mutational analysis of the pancreatic secretory trypsin inhibitor gene in familial and juvenile pancreatitis in Japan. J Gastroenterol 38: 365-370, 2003.

87. Ohmuraya M, Hirota M, Araki M, et al: Autophagic cell death of pancreatic acinar cells in serine protease inhibitor Kazal type 3-deficient mice. Gastroenterology 129: 696-705, 2005.

88. Rebours V, Couvelard A, Sauvanet A, et al: Pancreatic intraepithelial neoplasia is associated with chronic pancreatitis due to serine protease inhibitor kazal type 1 and cystic fibrosis transmembrane conductance regulator mutations. Pancreas 39 947-948, 2010.

89. Shimosegawa T, Kume K and Satoh K: Chronic pancreatitis and pancreatic cancer: prediction and mechanism. Clin Gastroenterol Hepatol 7 (11 Suppl): S23-S28, 2009.

90. Ogawa M, Matsuura N, Higashiyama K and Mori T: Expression of pancreatic secretory trypsin inhibitor in various cancer cells Res Commun Chem Pathol Pharmacol 55: 137-140, 1987.

91. Ozaki N, Ohmuraya M, Hirota M, et al: Serine protease inhibitor Kazal type 1 promotes proliferation of pancreatic cancer cells through the epidermal growth factor receptor. Mol Cancer Res 7: 1572-1581, 2009.

92. Ozaki N, Ohmuraya M, Ida S, et al: Serine protease inhibitor Kazal type 1 and epidermal growth factor receptor are expressed in pancreatic tubular adenocarcinoma, intraductal papillary mucinous neoplasm, and pancreatic intraepithelial neoplasia. J Hepatobiliary Pancreat Sci: Mar 12, 2013 (Epub ahead of print).

93. Oikawa T, Hitomi J, Kono A, et al: Frequent expression of genes for receptor tyrosine kinases and their ligands in human pancreatic cancer cells. Int J Pancreatol 18: 15-23, 1995.

94. Korc M, Friess H, Yamanaka Y, et al: Chronic pancreatitis is associated with increased concentrations of epidermal growth factor receptor, transforming growth factor alpha, and phospholipase C gamma. Gut 35: 1468-1473, 1994.

95. Tonouchi A, Ohtsuka M, Ito H, et al: Relationship between pancreatic secretory trypsin inhibitor and early recurrence of intrahepatic cholangiocarcinoma following surgical resection. Am J Gastroenterol 101: 1601-1610, 2006.
96. Gouyer V, Fontaine D, Dumont P, et al: Autocrine induction of invasion and metastasis by tumor-associated trypsin inhibitor in human colon cancer cells. Oncogene 27: 4024-4033, 2008.

97. Lo YY and Cruz TF: Involvement of reactive oxygen species in cytokine and growth factor induction of c-fos expression in chondrocytes. J Biol Chem 270: 11727-11730, 1995.

98. Liou GY and Storz P: Reactive oxygen species in cancer. Free Radic Res 44: 479-496, 2010.

99. Szatrowski TP and Nathan CF: Production of large amounts of hydrogen peroxide by human tumor cells. Cancer Res 51 794-798, 1991

100. Leung PS and Chan YC: Role of oxidative stress in pancreatic inflammation. Antioxid Redox Signal 11: 135-165, 2009.

101. Garcea G, Dennison AR, Steward WP and Berry DP: Role of inflammation in pancreatic carcinogenesis and the implications for future therapy. Pancreatology 5: 514-529, 2005.

102. Lau AT, He QY and Chiu JF: A proteome analysis of the arsenite response in cultured lung cells: evidence for in vitro oxidative stress-induced apoptosis. Biochem J 382: 641-650, 2004.

103. Lau AT and Chiu JF: Proteomic and biochemical analyses of in vitro carcinogen-induced lung cell transformation: synergism between arsenic and benzo[a]pyrene. Proteomics 6: 1619-1630, 2006.

104. Barchowsky A, Dudek EJ, Treadwell MD and Wetterhahn KE: Arsenic induces oxidant stress and NF-kappa B activation in cultured aortic endothelial cells. Free Radic Biol Med 21: 783-790, 1996

105. Schoenberg MH, Birk D and Beger HG: Oxidative stress in acute and chronic pancreatitis. Am J Clin Nutr 62 (6 Suppl): 1306S-1314S, 1995.

106. Kadlubar FF, Anderson KE, Häussermann S, et al: Comparison of DNA adduct levels associated with oxidative stress in human pancreas. Mutat Res 405: 125-133, 1998.

107. Cullen JJ, Mitros FA and Oberley LW: Expression of antioxidant enzymes in diseases of the human pancreas: another link between chronic pancreatitis and pancreatic cancer. Pancreas 26: 23-27, 2003.

108. Teoh ML, Sun W, Smith BJ, Oberley LW and Cullen JJ: Modulation of reactive oxygen species in pancreatic cancer. Clin Cancer Res 13: 7441-7450, 2007.

109. Benhar M, Engelberg D and Levitzki A: ROS, stress-activated kinases and stress signaling in cancer. EMBO Rep 3: 420-425, 2002.

110. Martindale JL and Holbrook NJ: Cellular response to oxidative stress: signaling for suicide and survival. J Cell Physiol 192: $1-15,2002$

111. Leonard SS, Harris GK and Shi X: Metal-induced oxidative stress and signal transduction. Free Radic Biol Med 37: 1921-1942, 2004

112. Shimojo Y, Akimoto M, Hisanaga T, et al: Attenuation of reactive oxygen species by antioxidants suppresses hypoxia-induced epithelial-mesenchymal transition and metastasis of pancreatic cancer cells. Clin Exp Metastasis 30: $143-154,2013$

113. DeNicola GM, Karreth FA, Humpton TJ, et al: Oncogene-induced Nrf2 transcription promotes ROS detoxification and tumorigenesis. Nature 475: 106-109, 2011.

114. Hossain MZ and Kleve MG: Nickel nanowires induced and reactive oxygen species mediated apoptosis in human pancreatic adenocarcinoma cells. Int J Nanomedicine 6 : 1475-1485, 2011.

115. Lau ST, Lin ZX and Leung PS: Role of reactive oxygen species in brucein D-mediated p38-mitogen-activated protein kinase and nuclear factor-kappaB signalling pathways in human pancreatic adenocarcinoma cells. Br J Cancer 102: 583-593, 2010.

116. Lin WW and Karin M: A cytokine-mediated link between innate immunity, inflammation, and cancer. J Clin Inves 117 1175-1183, 2007.

117. Mantovani A, Allavena P, Sica A and Balkwill F: Cancer-related inflammation. Nature 454: 436-444, 2008

118. Wigmore SJ, Fearon KC, Sangster K, Maingay JP, Garden OJ and Ross JA: Cytokine regulation of constitutive production of interleukin- 8 and -6 by human pancreatic cancer cell lines and serum cytokine concentrations in patients with pancreatic cancer. Int J Oncol 21: 881-886, 2002.

119. Talar-Wojnarowska R, Gasiorowska A, Smolarz B, et al: Clinical significance of interleukin-6 (IL-6) gene polymorphism and IL-6 serum level in pancreatic adenocarcinoma and chronic pancreatitis. Dig Dis Sci 54: 683-689, 2009. 
120. Miron N, Miron MM,Milea VG and Cristea V: Proinflammatory cytokines: an insight into pancreatic oncogenesis. Roum Arch Microbiol Immunol 69: 183-189, 2010.

121.Dima SO, Tanase C, Albulescu R, et al: An exploratory study of inflammatory cytokines as prognostic biomarkers in patients with ductal pancreatic adenocarcinoma. Pancreas 41: 1001-1007, 2012.

122. Matsuo Y, Takeyama H and Guha S: Cytokine network: new targeted therapy for pancreatic cancer. Curr Pharm Des 18: 2416-2419, 2012.

123. Maker AV, Katabi N, Qin LX, et al: Cyst fluid interleukin-1beta (IL1beta) levels predict the risk of carcinoma in intraductal papillary mucinous neoplasms of the pancreas. Clin Cancer Res 17: 1502-1508, 2011.

124. Wang CY, Mayo MW and Baldwin AS Jr: TNF- and cancer therapy-induced apoptosis: potentiation by inhibition of NF-kappaB. Science 274: 784-787, 1996.

125.Beg AA and Baltimore D: An essential role for NF-kappaB in preventing TNF-alpha-induced cell death. Science 274: 782-784, 1996.

126.McDade TP, Perugini RA, Vittimberga FJ Jr, Carrigan RC and Callery MP: Salicylates inhibit NF-kappaB activation and enhance TNF-alpha-induced apoptosis in human pancreatic cancer cells. J Surg Res 83: 56-61, 1999.

127. Baran B, Bechyne I, Siedlar M, et al: Blood monocytes stimulate migration of human pancreatic carcinoma cells in vitro: the role of tumour necrosis factor - alpha. Eur J Cell Biol 88: 743-752, 2009

128. Feurino LW, Zhang Y, Bharadwaj U, et al: IL-6 stimulates Th2 type cytokine secretion and upregulates VEGF and NRP-1 expression in pancreatic cancer cells. Cancer Biol Ther 6: 1096-1100, 2007.

129.Block KM, Hanke NT, Maine EA and Baker AF: IL-6 stimulates STAT3 and Pim-1 kinase in pancreatic cancer cell lines. Pancreas 41: 773-781, 2012.
130.Ebrahimi B, Tucker SL, Li D, Abbruzzese JL and Kurzrock R: Cytokines in pancreatic carcinoma: correlation with phenotypic characteristics and prognosis. Cancer 101: 2727-2736, 2004

131.Kamohara H, Takahashi M, Ishiko T, Ogawa M and Baba $\mathrm{H}$ : Induction of interleukin-8 (CXCL-8) by tumor necrosis factor-alpha and leukemia inhibitory factor in pancreatic carcinoma cells: Impact of CXCL-8 as an autocrine growth factor. Int J Oncol 31: 627-632, 2007.

132. Hussain F, Wang J, Ahmed R, et al: The expression of IL-8 and IL-8 receptors in pancreatic adenocarcinomas and pancreatic neuroendocrine tumours. Cytokine 49: 134-140, 2010.

133. Le X, Shi Q, Wang B, et al: Molecular regulation of constitutive expression of interleukin-8 in human pancreatic adenocarcinoma. J Interferon Cytokine Res 20: 935-946, 2000.

134. Xu X, Wang Y, Chen J, et al: High expression of CX3CL1/ CX3CR1 axis predicts a poor prognosis of pancreatic ductal adenocarcinoma. J Gastrointest Surg 16: 1493-1498, 2012.

135. Grote VA, Kaaks R, Nieters A, et al: Inflammation marker and risk of pancreatic cancer: a nested case-control study within the EPIC cohort. Br J Cancer 106: 1866-1874, 2012.

136. Schmieder A, Multhoff G and Radons J: Interleukin-33 acts as a pro-inflammatory cytokine and modulates its receptor gene expression in highly metastatic human pancreatic carcinoma cells. Cytokine 60: 514-521, 2012.

137. Bonifazi M, Gallus S, Bosetti C, et al: Aspirin use and pancreatic cancer risk. Eur J Cancer Prev 19: 352-354, 2010.

138. Bradley MC, Hughes CM, Cantwell MM, et al: Non-steroidal anti-inflammatory drugs and pancreatic cancer risk: a nested case-control study. Br J Cancer 102: 1415-1421, 2010.

139. Rothwell PM, Fowkes FG, Belch JF, et al: Effect of daily aspirin on long-term risk of death due to cancer: analysis of individual patient data from randomised trials. Lancet 377: 31-41, 2011. 